\title{
Chronic Obstructive Pulmonary Disease Is Associated with Altered Neuropsychological Performance in Young Adults
}

\author{
Antonella De Carolis ${ }^{a}$ Franco Giubilei ${ }^{a}$ Giulio Caselli ${ }^{a}$ \\ Barbara Casolla $^{a}$ Michele Cavallari ${ }^{a}$ Nicola Vanacore ${ }^{b}$ \\ Rita Leonoric ${ }^{c}$ Ilaria Scrocchia ${ }^{c}$ Anna Fersini ${ }^{c}$ \\ Augusto Querciac Francesco Orzi ${ }^{\mathrm{a}}$
}

${ }^{a}$ Department of Neuroscience, Mental Health and Sensory Organs, University of Rome La Sapienza, and ${ }^{\mathrm{b}}$ National Center of Epidemiology, Surveillance and Health Promotion, National Institute of Health, Rome, and ${ }^{C}$ PISLL, Azienda Unità Sanitaria Locale, Viterbo, Italy

\section{Key Words}

Alzheimer's disease $\cdot$ Chronic hypoxia $\cdot$ Chronic obstructive pulmonary disease $\cdot$ Hypoperfusion $\cdot$ Neuropsychological tests

\begin{abstract}
Background: Subjects with ischemic lesions have an increased risk of dementia. In addition, Alzheimer's disease (AD) and vascular cognitive impairment share many risk factors. These observations suggest that different diseases that cause altered blood perfusion of the brain or hypoxia promote AD neurodegeneration. In this case-control, cross-sectional study, we sought to test the hypothesis that hypoxia facilitates cognitive decline. Methods: We looked for altered neuropsychological performance in subjects with chronic obstructive pulmonary disease (COPD) without apparent cardio- or cerebrovascular diseases or risk factors for atherosclerosis. A selected, homogeneous group of workers from two ceramic factories in a small town of central Italy was enrolled in this study. Results: The COPD patients had a slightly, but significantly worse performance than controls in a number of neuropsychological tests. Conclusion: The findings are consistent with the working hypothesis that chronic hypoxia facilitates cognitive decline.




\section{Introduction}

In the brain of subjects with cognitive impairment, ischemic lesions often coexist with senile plaques and neurofibrillary tangles, the hallmarks of Alzheimer's disease (AD). The number or extent of the ischemic lesions strongly increases the odds of clinical dementia in persons with high levels of AD pathology $[1,2]$. In addition to being relevant to the clinical expression of the cognitive dysfunction, the infarcts may also reveal pathogenic aspects that are potentially common to AD and vascular cognitive impairment. A number of findings do in fact suggest that atherosclerosis or endothelial dysfunction of the brain vessels promotes the neurodegeneration associated with $\mathrm{AD}$ [3]. The hypothesis has received wide attention in the last years, mostly because of studies indicating that $\mathrm{AD}$ and vascular cognitive impairment share many risk factors [4]. Although the mechanisms by which a deregulated microcirculation would trigger AD are largely unknown [5], chronic hypoperfusion seems to play a crucial role. For instance, epidemiological data suggest a link between low blood pressure in older adults and cognitive decline [6]. Furthermore, hemodynamic microcirculatory insufficiency and hypometabolism (as demonstrated in mild cognitive impairment) seem to appear years before the onset of $\mathrm{AD}$, suggesting that the phenomena do not simply reflect the altered brain function $[7,8]$. Rats with permanent occlusion of both carotid arteries, a condition associated with low perfusion [9] and no acute histological damage, develop learning impairment and amyloid deposits [10]. The findings altogether suggest that different diseases that cause altered blood perfusion of the brain promote AD neurodegeneration. Thus, it is a consistent hypothesis that hypoperfusion plays a pathogenic role in AD neurodegeneration. A number of mechanisms have been proposed to be involved in mediating the effect of hypoperfusion. For instance, hypoperfusion can lead to overexpression of cyclindependent kinase 5 (CDK5), a serine-threonine kinase that is critical to synapse formation and synaptic plasticity [11-13].

The role of hypoxia in the hypothesized hypoperfusion-mediated neurodegeneration is also questioned. Chronic hypoxia, for instance, might mimic chronic hypoperfusion, implying that the deleterious effect of hypoperfusion is entirely mediated by the hypoperfusioninduced hypoxia. As an alternative, hypoperfusion might carry some additional pathogenic relevance, possibly because of hypoxia-independent mechanisms associated with dysfunction of the neurovascular unit. Of course, the issue has no easy answer, if not for the difficulty of defining 'chronic hypoxia' and 'chronic hypoperfusion'. There are, however, a few, inconclusive data favoring a role of chronic hypoxia per se. For instance, a longitudinal study showed that anemia, or low hemoglobin levels, in subjects with good baseline cognitive performance doubles the risk of developing dementia with respect to persons without anemia [14]. It is hypothesized, therefore, that chronic hypoxia promotes $\mathrm{AD}$ neurodegeneration, probably by causing mitochondrial dysfunction and activation of programmed cell death [15].

In order to address this issue, we assessed neuropsychological function in patients with chronic obstructive pulmonary disease (COPD) without apparent cardio- or cerebrovascular diseases, or risk factors for atherosclerosis in a small case-control study. For this purpose, we selected a group of workers from a ceramic factory in a small town of central Italy. The workers are at risk for COPD because of the exposure to silica dust.

\section{Methods}

\section{Subjects}

The study was carried out in subjects selected from a cohort of 955 workers from two ceramic factories in the province of Viterbo in central Italy. In a prevention program spon- 
sored by the government health system aiming to determine the risk of COPD associated with exposure to silica dust, the factory workers have been followed since 1994 by the Occupational Health Unit of Viterbo. The program includes periodic spirometric tests and acquisition of data for quantifying exposure to silica dust, expressed in terms of the cumulative exposure index as described previously [16].

A total of 89 subjects were found to meet the following inclusion criteria: age 35-65 years and diagnosis of COPD confirmed by a Tiffeneau index at the spirometric test $<70 \%$ [17]. An invitation letter to join the project resulted in 38 positive answers. The 38 eligible workers underwent an individual interview to assess the presence/absence of the following exclusion criteria: cognitive impairment (MMSE <26) and/or diagnosis of dementia, psychiatric disturbance, hypertension, alcoholism ( $>40 \mathrm{~g}$ of alcohol per day), diabetes, pharmacological treatment affecting cognitive function, systemic disease or cerebral lesions potentially affecting cognitive performance, severe visual or auditory impairment, low education $(<3$ years of formal school), or uncooperative behavior. Following the interview, a total of 16 cases were excluded, because of hypertension (8), diabetes mellitus (1), cardiac diseases, e.g. myocardial infarction or atrial fibrillation (4), liver (1) or thyroid disease (1), or depression (1). Of the 89 subjects, 22 cases were, therefore, included.

Controls were recruited from the remaining group of co-workers without COPD. Namely, individuals were randomly selected from the list of co-workers and included as controls, or rejected, on the basis of matching (age and gender) with one of the cases. The procedure was carried out until all the 22 cases had their own matching control. All the 44 subjects, 22 cases and 22 age- and sex-matched controls, underwent further spirometry assessment and completed a standard CECA (European Commission for Steel and Coal) questionnaire for chronic bronchitis and pulmonary emphysema [18] before study entry. All the 44 subjects included completed the study.

\section{Neuropsychological Assessment}

Cognitive performance was evaluated using a battery of neuropsychological tests generally employed in the clinical setting. The tests were selected to provide information about different areas of cognition: selective attention (visual search-attentional matrices; trail making test, part A) [19], cognitive flexibility/divided attention (trail making test, part B) [20], verbal long-term memory (story recall test) [21], verbal and spatial short-term memory (digit span/Corsi test) [21], non-verbal logical reasoning and problem-solving ability (Raven's colored progressive matrices) [22], word generation by phonological and semantic cues [phonological and semantic (animals) verbal fluency test] [21], auditory comprehension of complex sentences (token test) [20], spatial abilities and constructional praxis (copying drawings) [19]. The neuropsychological test battery was performed by a neuropsychologist who was blinded to the data on pulmonary function.

\section{Statistical Analysis}

Statistical analyses were performed by means of the $t$ test for unpaired data and Pearson's correlation. $\mathrm{p}<0.05$ was considered statistically significant. All analyses were performed using the Statistical Package for the Social Sciences (SPSS, version 13.0).

\section{Results}

Demographic and occupational variables of the subjects are shown in table 1. All the subjects were male, and had similar age and educational level. There was no difference between the two groups in the length of continuous service in the factory as well as in the cu- 
Table 1. Demographic and occupational data on the study groups

\begin{tabular}{lccl}
\hline & $\begin{array}{l}\text { COPD group } \\
(\mathrm{n}=22)\end{array}$ & $\begin{array}{l}\text { Control group } \\
(\mathrm{n}=22)\end{array}$ & $\begin{array}{l}\mathrm{p} \\
\text { value }\end{array}$ \\
\hline Age, years & $50 \pm 7$ & $47 \pm 5$ & $\mathrm{NS}$ \\
Length of service, years & $26 \pm 8$ & $25 \pm 8$ & $\mathrm{NS}$ \\
Cumulative exposure indices to silica dust & $12 \pm 19$ & $11 \pm 18$ & NS \\
Education, school years & $8 \pm 2$ & $9 \pm 3$ & NS \\
Smoking status, packs/year & $547 \pm 449$ & $315 \pm 210$ & NS \\
\hline
\end{tabular}

NS $=$ Nonsignificant $(p>0.05)$. Four subjects in the control and none in the COPD group were never smokers.

Table 2. Tiffeneau index values in patients with COPD and controls

\begin{tabular}{llll}
\hline Groups & Mean & SD & Range \\
\hline COPD & 61 & 9 & $39-70$ \\
Control & 79 & 5 & $70-88$ \\
\hline
\end{tabular}

Fig. 1. Differences in neuropsychological evaluation between COPD patients and controls. Each bar represents the mean \pm SD percent difference compared to the controls. Raven = Raven's colored progressive matrices; TMA $/ \mathrm{TMB}=$ trail making test part A/part B; VS = visual search; $\mathrm{SR}=$ story recall; Corsi $=$ Corsi test; Digit = digit span test; Token = token test; $\mathrm{PF}=$ phonological fluency; $\mathrm{SF}$ = semantic fluency; $\mathrm{CD}=$ copying drawings. ${ }^{*} \mathrm{p} \leq 0.05 ;{ }^{* *} \mathrm{p} \leq 0.01$.

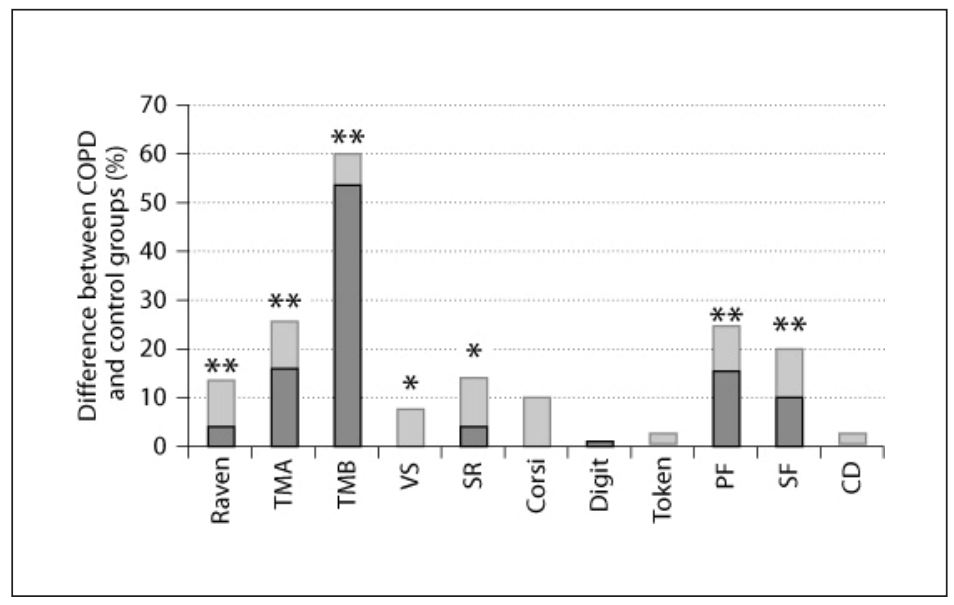

mulative exposure index to silica dust. Smoking habits, expressed as number of packets of cigarettes per year, was slightly different $(\mathrm{p}=0.053)$ between COPD and control groups. The mean $( \pm S D)$ duration of COPD was $5 \pm 2$ years (range $2-7$ ). The Tiffeneau indices of all the subjects are reported in table 2 .

The MMSE score was significantly different between COPD subjects and controls (mean \pm SD, $29 \pm 1$ and $30 \pm 1$, respectively, $\mathrm{p}=0.004$ ). Furthermore, patients with COPD had lower scores than controls in a number of different tests, including Raven's colored progressive matrices $(\mathrm{p}=0.001)$, trail making parts $\mathrm{A}$ and $\mathrm{B}(\mathrm{p}=0.010$ and $\mathrm{p}=0.001$, respectively), visual search $(\mathrm{p}=0.019)$, story recall $(\mathrm{p}=0.023)$, and phonological and semantic fluency ( $p=0.001$ and $p=0.003$, respectively; table 3; fig. 1 ). Pearson's correlation analysis showed a correlation between the Tiffeneau index and MMSE $(p=0.019)$. 
Table 3. Neuropsychological tests performed in the study groups

\begin{tabular}{lccc}
\hline Tests & $\begin{array}{l}\text { COPD group } \\
(\mathrm{n}=22)\end{array}$ & $\begin{array}{l}\text { Control group } \\
(\mathrm{n}=22)\end{array}$ & $\begin{array}{l}\mathrm{p} \\
\text { value }\end{array}$ \\
\hline Raven's colored progressive matrices & $28 \pm 5$ & $32 \pm 3$ & 0.001 \\
Trail making A & $43 \pm 12$ & $34 \pm 8$ & 0.010 \\
Trail making B & $116 \pm 52$ & $72 \pm 25$ & 0.001 \\
Visual search & $66 \pm 7$ & $71 \pm 7$ & 0.019 \\
Story recall & $14 \pm 3$ & $16 \pm 3$ & 0.023 \\
Corsi & $4 \pm 1$ & $5 \pm 1$ & $\mathrm{NS}$ \\
Digit span & $5 \pm 1$ & $5 \pm 1$ & $\mathrm{NS}$ \\
Token & $33 \pm 2$ & $33 \pm 1$ & $\mathrm{NS}$ \\
Phonological fluency & $24 \pm 7$ & $32 \pm 8$ & 0.001 \\
Semantic fluency & $16 \pm 4$ & $20 \pm 4$ & 0.003 \\
Copying drawings & $12 \pm 1$ & $13 \pm 1$ & $\mathrm{NS}$ \\
\hline
\end{tabular}

Means \pm SD of the scores reported at each test in the COPD and control groups. NS = Nonsignificant $(\mathrm{p}>0.05)$.

\section{Discussion}

The results of this study show that people with COPD had a slightly, but significantly worse performance than controls in a number of neuropsychological tests. The two groups specifically differed in tests that refer to executive function, attention, non-verbal logical reasoning and problem-solving ability, verbal long-term memory and language. The data suggest an involvement of both subcortical and cortical functions.

We hypothesize that the altered performance in the COPD group is attributable to brain dysfunction associated with chronic hypoxia. The occurrence of hypoxia in COPD can be inferred on the basis of a number of studies [23]. Because of ethical concerns regarding the invasiveness of the procedure, in fact, we did not perform any measurement of partial pressure of oxygen in arterial blood in our participants.

A few, mostly anecdotal, reports have previously indicated the likelihood of an association between COPD and cognitive impairment [24], with impairment being diffuse [25, 26] or confined to immediate [27] or verbal memory [28]. Our findings of an involvement of both subcortical and cortical functions are at odds with previous data obtained in an inhomogeneous group of subjects hospitalized for COPD [24].

A potential confounding variable in the interpretation of our data concerns cigarette smoking. There was, in fact, a slight difference between the two groups in the number of cigarettes smoked per year $(\mathrm{p}=0.053)$. Smoke may have a role in the pathogenesis of COPD. Smoke is a controversial risk factor for cognitive impairment in midlife $[19,29]$ and is also an independent risk factor for cerebrovascular diseases [30]. Therefore, we cannot rule out an underlying, asymptomatic, ischemic brain pathology that would account for the cognitive difference between the two groups. The hypothesis, however, seems unlikely in view of the relatively young age of the subjects and the careful exclusion of vascular risk factors in the selection of the subjects. Furthermore, correlation analyses showed no association between smoking status (expressed in packs/year) and neuropsychological performance (data not shown).

The subjects were included following a progressive refusal/exclusion procedure. Such a recruitment method, together with the small sample size, represents a limitation of the study 
that might raise the doubt of a sample bias. However, the findings gain strength from the distinctive homogeneity of the population examined in this report. It is worth stressing that both COPD and control subjects have been living in the very same small town and have been working in the same factory for $>20$ years. In addition, all the individuals enrolled have a similar education/social background. All of them have had periodic assessments of respiratory function for $>5$ years, and the medical records allowed us to exclude cerebrovascular diseases or other potentially confounding factors.

In conclusion, the results of this study are consistent with the working hypothesis that chronic hypoxia facilitates cognitive decline.

\section{Acknowledgments}

The study was supported by the Scientific Research and University Department of Italy, project 'COFIN' 2004.

\section{References}

1 de la Torre JC: Alzheimer disease as a vascular disorder: nosological evidence. Stroke 2002;33:11521162.

-2 Snowdon DA, Greiner LH, Mortimer JA, Riley KP, Greiner PA, Markesbery WR: Brain infarction and the clinical expression of Alzheimer disease. The Nun Study. JAMA 1997;277:813-817.

-3 de la Torre JC: Is Alzheimer's disease preceded by neurodegeneration or cerebral hypoperfusion? Ann Neurol 2005;57:783-784.

4 Gorelick PB: Risk factors for vascular dementia and Alzheimer disease. Stroke 2004;35:2620-2622.

-5 Iadecola C, Gorelick PB: Converging pathogenic mechanisms in vascular and neurodegenerative dementia. Stroke 2003;34:335-337.

-6 Qiu C, Winblad B, Fratiglioni L: The age-dependent relation of blood pressure to cognitive function and dementia. Lancet Neurol 2005;4:487-499.

-7 Chetelat G, Desgranges B, de la Sayette V, Viader F, Eustache F, Baron JC: Mild cognitive impairment: can FDG-PET predict who is to rapidly convert to Alzheimer's disease? Neurology 2003;60:1374-1377.

$\checkmark 8$ de la Torre JC: Critically attained threshold of cerebral hypoperfusion: can it cause Alzheimer's disease? Ann NY Acad Sci 2000;903:424-436.

-9 Otori T, Katsumata T, Muramatsu H, Kashiwagi F, Katayama Y, Terashi A: Long-term measurement of cerebral blood flow and metabolism in a rat chronic hypoperfusion model. Clin Exp Pharmacol Physiol 2003;30:266-272.

-10 Bennett SA, Pappas BA, Stevens WD, Davidson CM, Fortin T, Chen J: Cleavage of amyloid precursor protein elicited by chronic cerebral hypoperfusion. Neurobiol Aging 2000;21:207-214.

-11 Cheung ZH, Gong K: Cyclin-dependent kinase 5 supports neuronal survival through phosphorylation of Bcl-2. J Neurosci 2008;28:4872-4877.

-12 Weishaupt JH, Kussmaul L, Grotsch P, Heckel A, Rohde G, Romig H, Bahr M, Gillardon F: Inhibition of CDK5 is protective in necrotic and apoptotic paradigms of neuronal cell death and prevents mitochondrial dysfunction. Mol Cell Neurosci 2003;24:489-502.

-13 Wen Y, Yang SH, Liu R, Perez EJ, Brun-Zinkernagel AM, Koulen P, Simpkins J: Cdk5 is involved in NFT-like tauopathy induced by transient cerebral ischemia in female rats. Biochim Biophys Acta 2007; 1772:473-483.

-14 Atti AR, Palmer K, Volpato S, Zuliani G, Winblad B, Fratiglioni L: Anaemia increases the risk of dementia in cognitively intact elderly. Neurobiol Aging 2006;27:278-284.

-15 Bazan NG, Palacios-Pelaez R, Lukiw WJ: Hypoxia signaling to genes: significance in Alzheimer's disease. Mol Neurobiol 2002;26:283-298.

-16 Forastiere F, Goldsmith DF, Sperati A, Rapiti E, Miceli M, Cavariani F, Perucci CA: Silicosis and lung function decrements among female ceramic workers in Italy. Am J Epidemiol 2002;156:851-856. 
17 Pauwels RA, Buist AS, Calverley PM, Jenkins CR, Hurd SS: Global strategy for the diagnosis, management, and prevention of chronic obstructive pulmonary disease. NHLBI/WHO Global Initiative for Chronic Obstructive Lung Disease (GOLD) Workshop summary. Am J Respir Crit Care Med 2001;163:1256-1276.

-18 Quanjer PH (ed): Standardised lung function testing. Report Working Party. Standardisation of lung function tests. European Community for Coal and Steel, Luxembourg. Bull Eur Physiopathol Respir 1983;19:1-95.

-19 Spinnler H, Tognoni G: Standardizzazione e taratura Italiana di test neuropsicologici. Ital J Neurol Sci 1987;8:1-120.

-20 Giovagnoli AR, Del Pesce M, Mascheroni S, Simoncelli M, Laiacona M, Capitani E: Trail making test: normative values from 287 normal adult controls. Ital J Neurol Sci 1996;17:305-309.

-21 Novelli G, Papagno C, Capitani E, Laiacona M, Vallar G, et al: Tre test clinici di ricerca e produzione lessicale. Taratura su soggetti normali. Arch Psicol Neurol Psichiatr 1986;47:477-506.

-22 Basso A, Capitani E, Laiacona M: Raven's coloured progressive matrices: normative values on 305 adult normal controls. Funct Neurol 1987;2:189-194.

-23 Kutty K: Sleep and chronic obstructive pulmonary disease. Curr Opin Pulm Med 2004;10:104-112.

-24 Antonelli Incalzi R, Marra C, Giordano A, Calcagni ML, Cappa A, Basso S, Pagliari G, Fuso L: Cognitive impairment in chronic obstructive pulmonary disease - a neuropsychological and SPECT study. J Neurol 2003;250:325-332.

-25 Grant I, Heaton RK, McSweeny AJ, Adams KM, Timms RM: Neuropsychologic findings in hypoxemic chronic obstructive pulmonary disease. Arch Intern Med 1982;142:1470-1476.

-26 Incalzi RA, Gemma A, Marra C, Capparella O, Fuso L, Carbonin P: Verbal memory impairment in COPD: its mechanisms and clinical relevance. Chest 1997;112:1506-1513.

-27 Fioravanti M, Nacca D, Amati S, Buckley AE, Bisetti A: Chronic obstructive pulmonary disease and associated patterns of memory decline. Dementia 1995;6:39-48.

- 28 Incalzi RA, Gemma A, Marra C, Muzzolon R, Capparella O, Carbonin P: Chronic obstructive pulmonary disease. An original model of cognitive decline. Am Rev Respir Dis 1993;148:418-424.

- 29 Richards M, Jarvis MJ, Thompson N, Wadsworth ME: Cigarette smoking and cognitive decline in midlife: evidence from a prospective birth cohort study. Am J Public Health 2003;93:994-998.

-30 Iribarren C, Darbinian J, Klatsky AL, Friedman GD: Cohort study of exposure to environmental tobacco smoke and risk of first ischemic stroke and transient ischemic attack. Neuroepidemiology 2004;23:38-44. 